\title{
RECONSTRUÇÃO DIGITAL DO PATRIMÔNIO ARQUITETÔNICO PARA AMBIENTES VIRTUAIS INTERATIVOS 3D: ESTUDO DE MÉTODOS PARA MODELAGEM GEOMÉTRICA DE EDIFICAÇÕES EXISTENTES
}

\author{
DIGITAL RECONSTRUCTION OF ARCHITECTURAL HERITAGE FOR 3D INTERACTIVE \\ VIRTUAL ENVIRONMENTS: STUDY OF METHODS FOR GEOMETRIC MODELING OF \\ EXISTING BUILDINGS
}

\author{
Gabriela Linhares da Silva ${ }^{1}$, Natalie Johanna Groetelaars ${ }^{1}$
}

\section{RESUMO:}

Com os constantes avanços tecnológicos, novas formas de documentação digital do patrimônio têm surgido, permitindo a reconstrução virtual de edificações e sítios de interesse histórico e cultural. $\mathrm{O}$ uso de ambientes virtuais interativos, como em aplicações de realidade virtual e jogos digitais, estão cada vez mais sendo estudados para utilização em diversas áreas, buscando métodos mais interativos e imersivos de aprendizado. O surgimento de ferramentas gratuitas que otimizam o desenvolvimento dessas aplicações, como os game engines, permitem a elaboração de formas inovadoras de conhecer e interagir com o patrimônio edificado, que podem ser compartilhadas online e através de diferentes dispositivos móveis, facilitando o acesso a esse bem. Este artigo tem por objetivo: investigar, por meio de um estudo prático, diferentes métodos e técnicas de modelagem geométrica de edificações existentes de interesse histórico; inserir os diferentes modelos gerados na ferramenta Unreal Engine 4; por fim, realizar uma análise comparativa da visualização desses modelos, identificando qual o melhor workflow para a representação dessas edificações, visando o futuro desenvolvimento de um ambiente virtual interativo 3D.

PALAVRAS-CHAVE: Patrimônio cultural edificado; Digitalização 3D; Modelo geométrico; Nuvem de pontos.

\begin{abstract}
:
With the constant advance of technology, new means of digital heritage documentation have emerged, allowing the virtual reconstruction of buildings and sites of historical and cultural interest. The use of interactive virtual environments, as in virtual reality applications and digital games, are increasingly being studied for use in several areas, researching more interactive and immersive learning methods. The emergence of free tools that optimize the development of these applications, such as game engines, allow the development of innovative ways of knowing and interacting with the built heritage, which can be shared online and through different mobile devices, facilitating the access to this asset. This article aims to: investigate, through a practical study, different methods and techniques of geometric modeling of existing buildings of historical interest; insert the different models generated in Unreal Engine 4 tool; finally, make a comparative analysis of the visualization of these models, identifying which is the best workflow for the representation of these buildings, aiming the future development of an 3D interactive virtual environment.
\end{abstract}

KEYWORDS: Built cultural heritage; 3D digitization; Geometric model; Point cloud.
1Universidade Federal da Bahia

Fonte de Financiamento: CNPq - Conselho Nacional de Desenvolvimento Científico e Tecnológico

Conflito de Interesse: Declara não haver.

Ética em Pesquisa: Declaro não haver necessidade.

Submetido em: 13/07/2020 Aceito em: 18/02/2021

How to cite this article:

LINHARES, G.; GROETELAARS, N. J. Reconstrução digital do patrimônio arquitetônico para ambientes virtuais interativos 3D: estudo de métodos para modelagem geométrica de edificações existentes. Gestão \& Tecnologia de Projetos. São Carlos, v16, n3, 2021. https://doi.org/10.11606/gtp.v16i3.172369 


\section{INTRODUÇÃO}

A documentação do patrimônio cultural é um tema de grande relevância e que vem despertando um interesse crescente de diversos pesquisadores e profissionais na busca de soluções mais eficientes e eficazes para a preservação e difusão do mesmo. As edificações de interesse histórico e cultural, que constituem o acervo patrimonial arquitetônico, representam, além de seu valor artístico, a identidade, tradição e memória de uma determinada época, configurando-se como herança insubstituível para as gerações futuras. No Brasil, a maior parte desses bens não possui registros precisos e fidedignos (GROETELAARS, 2015), ou sequer foram documentados. Seja pelas ações do tempo e da natureza, junto à impossibilidade de resguardar o acervo arquitetônico em locais protegidos, ou pela degradação proveniente da falta de manutenção e do abandono do próprio ser humano (AMORIM, 2011), o patrimônio arquitetônico está sujeito ao desaparecimento.

Nesse contexto, as tecnologias digitais têm proporcionado novas formas e ferramentas para a documentar e difundir o patrimônio arquitetônico, possibilitando a reconstrução digital de monumentos ou locais que não mais existem, até a representação realista de edificações e sítios existentes. Conforme afirma Nogueira (2010, p. 15) "[...] onde as técnicas tradicionais de documentação e representação se mostram insuficientes, as tecnologias digitais [...] proporcionam uma gama de aplicações", cujas vantagens vão, segundo o autor, desde a rapidez e precisão na aquisição de dados até a facilidade para atualizar e armazenar informações, assim como para difundi-las.

0 uso das tecnologias digitais nesse processo de documentação trouxe o conceito de patrimônio digital (ou virtual), reconhecido em 2003 pela Carta sobre a Preservação do Patrimônio Digital e descrito por Champion (2015, p. 5, tradução nossa) como "[...] tentativa de transmitir não apenas a aparência, mas também o significado e a importância dos artefatos culturais [...] através da utilização de mídias digitais interativas e imersivas".

A Carta de Londres de 2009 ressalta a importância de que a visualização computadorizada do patrimônio apresente rigor científico e destaca questões como integridade, fidelidade, documentação, sustentabilidade e acesso. Ressalta também que as formas de documentação e visualização digitais devem melhorar o acesso ao patrimônio cultural, proporcionado "[...] a possibilidade de estudar as mudanças ocorridas ao longo do tempo, ampliações, modificações, manipulação de objetos virtuais, integração em base de dados e imediata distribuição global." (DRENARD, 2009, p. 12, tradução nossa).

Diversas tecnologias digitais vêm sendo estudadas como forma de documentar e difundir o patrimônio, com destaque para o uso de Ambientes Virtuais Interativos (AVI). 0 uso de AVI na arquitetura simula novas experiências imersivas que dialogam com o espaço em suas diversas escalas, construindo novas narrativas e proporcionando formas renovadas de interação com o usuário por meio de interfaces digitais (MARCHI; HASHIMOTO, 2018).

Com o crescente avanço da tecnologia, novas ferramentas têm surgido para a criação desses AVI, bem como equipamentos para visualização imersiva. A partir do uso de AVI, a Realidade Virtual (RV) ganhou destaque nas últimas décadas, trazendo novas formas interativas de visualizar reconstituições virtuais 3D e de compreensão dos bens tangíveis e intangíveis, deixando de lado a percepção de um patrimônio cultural petrificado e proporcionando diferentes maneiras de experimentar o espaço construído (IOANNIDES; MAGNENATTHALMANN; PAPAGIANNAKIS, 2017).

Outra área que se tornou predominante no desenvolvimento de AVI foi a dos jogos digitais, que têm como características principais serem ambientes virtuais completamente interativos, onde o usuário faz escolhas, toma decisões e controla suas ações. Essas questões são 
valorizadas no processo de aprendizagem, uma vez que criam uma relação afetiva com esses ambientes e podem favorecer na identificação, valorização e compreensão do patrimônio cultural (CAMARA, 2018).

Uma das principais etapas no processo de criação de AVI é a geração de modelos geométricos. No contexto do patrimônio arquitetônico, a modelagem geométrica (3D) tem por finalidade a representação digital de edificações ou sítios de interesse histórico e cultural (contemplando as características consideradas imprescindíveis para o reconhecimento dos mesmos), que pode ser feita em diferentes níveis de detalhe, a depender do objetivo final da aplicação.

A modelagem geométrica de edificações históricas pode ser realizada, fundamentalmente, a partir de duas situações: (1) edificações que não existem mais, quando se usam geralmente documentos históricos, dados cadastrais e fotografias para servirem de base para a reconstituição digital; ou (2) edificações existentes, quando podem ser utilizadas as tecnologias digitais para a aquisição de dados geométricos e texturas, com destaque para a Fotogrametria Digital e o 3D Laser Scanning.

A criação de modelos geométricos de edificações existentes para o uso em ambientes virtuais interativos é um processo complexo. Exige a conciliação entre um modelo preciso e fidedigno à edificação representada (com um nível de detalhe adequado para o reconhecimento e a compreensão da mesma), e um modelo que possa ser facilmente processado pela aplicação interativa em tempo real, o que requer um arquivo de tamanho reduzido e com uma quantidade otimizada do número de polígonos que representam os objetos. Para isso, torna-se necessário o conhecimento de técnicas e softwares para modelagem geométrica que possibilitem a simplificação do modelo sem perder a qualidade visual.

Este artigo apresenta inicialmente as etapas de criação de ambientes virtuais interativos 3D voltados ao patrimônio arquitetônico, com foco na etapa de modelagem geométrica de edificações existentes. Apresenta a investigação de diferentes métodos, técnicas e softwares para modelagem geométrica, por meio de um estudo prático com diversos workflows, visando à obtenção de diferentes tipos de modelos geométricos fotorrealísticos, tomando-se como base o modelo texturizado gerado por restituição fotogramétrica digital. Por fim, analisa e compara a visualização, em um game engine ${ }^{\text {i }}$ dos modelos obtidos, com o propósito de identificar qual o workflow mais adequado para a representação digital de edificações históricas existentes, considerando-se as seguintes questões: a posterior criação de um ambiente virtual interativo; a qualidade gráfica final do modelo; o nível de detalhe e precisão em relação à edificação original; o número total de polígonos do modelo e o tamanho final do arquivo

\section{AMBIENTES VIRTUAIS INTERATIVOS 3D}

Ambientes virtuais podem ser descritos como espaços gerados por um computador, ou ambientes sintéticos compostos por objetos virtuais, e que têm por objetivo envolver a atenção do usuário (JERALD, 2016). Embora a terminologia tenha surgido a partir da ideia de colocar as pessoas em espaços sintéticos tridimensionais (ROSA JÚNIOR, 2003), a definição de ambientes virtuais hoje inclui diversas características que possibilitam diferentes tipos de classificação, como bidimensionais ou tridimensionais, passivos ou interativos, de uso individual ou de uso compartilhado, entre outros.

\section{CARACTERÍSTICAS DOS AVI 3D}

O objeto de estudo deste trabalho limita-se aos ambientes virtuais voltados exclusivamente para o patrimônio arquitetônico e que apresentam as seguintes características: interatividade, processamento em tempo real, tridimensionalidade e que busquem proporcionar ao usuário a 
sensação de presença no ambiente sintético criado. AVI com essas características representam uma parte fundamental das aplicações de realidade virtual, podendo esta ser resumida como: um conjunto de métodos, tecnologias e interface usuário-sistema que permitem a interação com o AVI, tendo como objetivo principal proporcionar ao usuário a máxima sensação de estar vivenciando o ambiente sintético.

Muitos jogos digitais também funcionam, essencialmente, a partir de AVI e vêm ganhando, nas últimas décadas, um grande destaque na exibição de ambientes virtuais realistas e imersivos. Esses jogos digitais proporcionam experiências altamente interativas e adaptáveis a diversos aparelhos eletrônicos, desde os computadores de mesa e videogames até smartphones e tablets. Muitos desses jogos têm apresentado AVI de grande complexidade, diversas possibilidades de interação e grandes cenários tridimensionais exploráveis. Isso foi possível devido aos avanços da computação, que proporcionaram o aumento da capacidade de processamento em tempo real, permitindo a interação dos usuários com cenários realistas e tornando os jogos digitais um grande sucesso (ANDERSON et al., 2009).

McGonigal (2010) explica que os gráficos imersivos, os sons e o próprio ambiente tridimensional realista aumentam a atenção do usuário à atividade que desenvolvem no jogo, criando uma motivação para o desenvolvimento de ações e para a aquisição de conhecimento dentro desse ambiente virtual. Esse potencial inerente aos jogos digitais, que também é encontrado nas aplicações de realidade virtual, pode ser utilizado também em aplicações voltadas para o patrimônio, como exemplificado em diversas pesquisas realizadas nesse campo (MORTARA et al., 2014; IOANNIDES; MAGNENAT-THALMANN; PAPAGIANNAKIS, 2017; CAMARA, 2018; STATHAM, 2019; LINHARES; GROETELAARS, 2019a).

Durante as últimas décadas, as potencialidades dos jogos também vêm sendo exploradas através do processo de gamificação ${ }^{i i}$ para o desenvolvimento de aplicações voltadas ao patrimônio. Uma outra aplicação que se desenvolve nesse contexto é o Serious Game (SG), um jogo com o objetivo de levar o jogador a cumprir metas de aprendizagem de uma forma mais lúdica (MORTARA et al., 2014). Diversos tipos de aplicações interativas em 3D trabalham, portanto, com a reconstituição de edificações ou locais existentes, proporcionando cenários realistas e possibilitando uma percepção diferenciada dos espaços, de forma interativa e estimulante, e que podem ser disponibilizados online para o mundo.

E no desenvolvimento desse tipo de aplicação interativa, os game engine têm ganhado destaque na geração dos mais diferentes tipos de AVI devido a algumas de suas características, como: interface simplificada e intuitiva; possibilidade de criação do ambiente virtual interativo em tempo real; alternativa de uma programação mais visual, sem a necessidade de conhecimentos aprofundados em linguagens de códigos; permitir importar modelos geométricos texturizados de diferentes softwares de modelagem, como Blender, Maya, 3DS Max, Rhinoceros, Sketchup, Revit, entre outros; e vasta comunidade virtual de usuários que fornecem tutoriais gratuitos e fóruns de ajuda. Essas características facilitam o uso dos game engines por profissionais de diferentes áreas para criar desde jogos digitais e ambientes de realidade virtual imersiva, até AVI não imersivos com interações simplificadas.

Assim, os game engines permitem a criação de aplicações para visualização 3D interativas de amplos espaços, a exploração imersiva de locais reconstituídos digitalmente, a adição de recursos visuais e de informações, e possibilitam um alto grau de controle por parte do usuário para interagir no ambiente virtual (STATHAM, 2019). Com o uso de scripts, templates préprogramados e bibliotecas digitais, essas plataformas simplificam e agilizam o desenvolvimento de aplicações gráficas em tempo real. 


\section{ETAPAS PARA CRIAÇÃO DOS AVI 3D}

A partir do mapeamento de aplicações de ambientes virtuais interativos voltados para o patrimônio, realizado em pesquisa anterior (LINHARES; GROETELAARS, 2019a), foram identificadas as principais etapas para a criação desses AVI. A Figura 1 ilustra essas etapas (ou estágios), dividindo-as em duas grandes fases: 1. Planejamento e 2. Implementação.

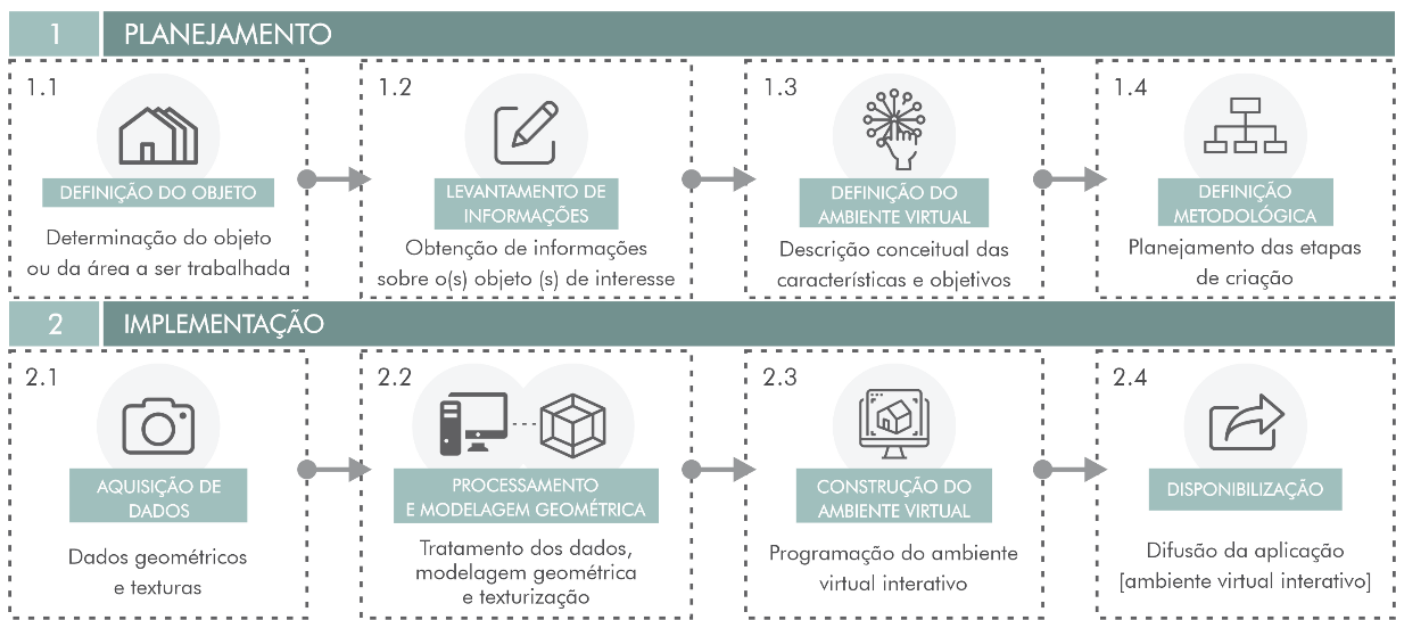

A primeira fase consiste no planejamento do ambiente virtual interativo 3D, onde são realizadas as seguintes etapas: 1.1. Definição do objeto (edificação ou conjunto urbano de interesse histórico e cultural) a ser trabalhado; 1.2. Levantamento das informações disponíveis sobre o objeto e análise das mesmas, de forma a identificar os dados disponíveis, as condicionantes do local e qual a melhor forma de trabalhar com essas informações; 1.3. Definição do ambiente virtual a ser criado (características, objetivos da aplicação e forma de difusão), em função do tempo, recursos e informações disponíveis; 1.4. Definição metodológica, que consiste na escolha dos métodos, técnicas e ferramentas a serem utilizados em cada estágio do desenvolvimento da aplicação.

Na segunda fase são apresentados os estágios do processo de implementação do AVI 3D, cujas particularidades dependem da metodologia definida anteriormente. A etapa 2.1. Aquisição de dados consiste na obtenção de dados geométricos, texturas, detalhes e todas as informações que forem consideradas importantes para a reconstrução digital do objeto, podendo utilizarse de métodos tradicionais (como a medição direta ou uso de plantas cadastrais como base para a modelagem geométrica) ou de tecnologias digitais, como varredura a laser e/ou tomada fotográfica para restituição fotogramétrica na etapa posterior. 0 estágio 2.2. Processamento e modelagem geométrica pode ser resumido ao tratamento dos dados adquiridos na etapa de aquisição (como processamento das imagens para geração de modelos de nuvens de pontos) e ao posterior processo de modelagem geométrica, que pode ser baseada em processos tradicionais (medidas, desenhos, etc.) ou apoiada em modelos gerados por sistemas de varredura.

A etapa 2.3. Construção do AVI pode ser descrita como a estruturação do espaço tridimensional com os modelos geométricos produzidos e a programação da aplicação, onde são elaboradas as formas de interatividade, as informações que serão exibidas e a interface com o usuário. E o estágio 2.4. Disponibilização representa a difusão do ambiente virtual criado, que pode ser feita online por meio de: websites, equipamentos fixos em locais predeterminados ou aplicativos instalados em dispositivos móveis.
Figura 1. Etapas de desenvolvimento de ambientes virtuais interativos 3D

Fonte: Adaptado de Linhares e Groetelaars (2019a). 
Figura 2. Etapas da modelagem

geométrica com o uso tecnologias digitais para a aquisição de dados

Fonte: Elaboração das autoras.

Figura 3. Etapas da modelagem

geométrica com o uso de técnicas

tradicionais para a aquisição de dados

Fonte: Elaboração das autoras.
Após o aprofundamento da pesquisa nas etapas de desenvolvimento de AVI 3D, com foco na etapa de modelagem geométrica, foram elaborados dois esquemas gráficos representativos do processo de modelagem de edificações existentes, em função do uso de tecnologias digitais (Figura 2) ou de técnicas manuais para a aquisição de dados (Figura 3).

\section{MODELAGEM GEOMÉTRICA
[TECNOLOGIAS DIGITIS]}

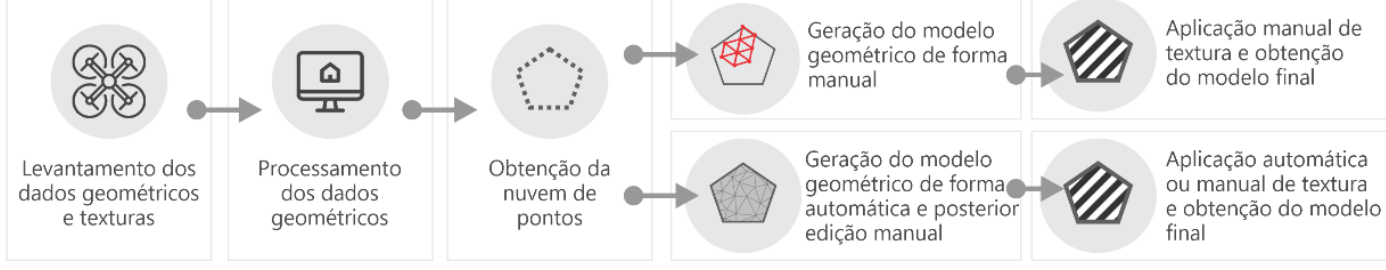

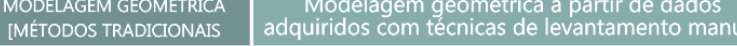
adquiridos com tecnicas de levantamento manual

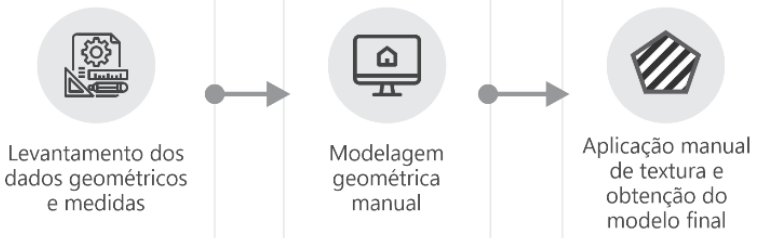

A modelagem geométrica de edificações existentes a partir do uso de dados adquiridos por meio de tecnologias digitais compreende os seguintes processos: (1) levantamento dos dados geométricos e texturas, que pode ser feito com o uso de câmeras fotográficas (seja através de sistemas terrestres ou aerotransportados) ou por meio do 3D Laser Scanning; (2) processamento dos dados, que pode ser feito através da técnica Dense Stereo Matching (DSM), onde é realizado o processamento automatizado das fotografias por um software para restituição fotogramétrica; (3) obtenção da nuvem de pontos, resultado do processamento das fotografias (aéreas e/ou terrestres) ou do escaneamento a laser; (4) geração e edição do modelo geométrico, que pode ser obtido de forma automatizada mediante o processamento da nuvem de pontos para geração da malha triangular irregular, ou de forma manual, modelando o objeto desde o início com base na nuvem de pontos ou a partir da incorporação de outras etapas de processamento; (5) aplicação da textura no modelo geométrico final (mapeamento da textura), que pode também ser feita de forma automática em modelos originados por meio de processo automático, ou pode ser realizada de modo manual.

Já a modelagem geométrica de edificações existentes a partir do uso de dados adquiridos com técnicas tradicionais de levantamento (como a medição direta), por mais que apresente um fluxo de trabalho com menos etapas, resultam em um procedimento que demanda mais tempo e custo e apresenta maiores limitações. Todo o processo, desde a aquisição de dados até a modelagem, é feito de modo manual, com limitações para aquisição de dados e para a modelagem geométrica, especialmente em se tratando de objetos de grandes dimensões e com formas mais complexas. Este método compreende as seguintes etapas: (1) levantamento dos dados geométricos e medidas da edificação, feito com o auxílio de trenas e outros equipamentos tradicionais; (2) modelagem geométrica, onde o objeto é inteiramente modelado de forma manual a partir das medidas e informações obtidas na etapa anterior; (3) aplicação manual de texturas genéricas no modelo, ou de texturas realistas obtidas de fotografias do objeto. 
Ambos os métodos resultam em processos complexos que necessitam de etapas manuais, do conhecimento em softwares de modelagem geométrica e de mapeamento de texturas. Também é necessário entender os diferentes tipos de modelos geométricos que podem ser gerados: modelos de malha densa, com alta contagem de polígonos e que permitem melhor representação de formas geométricas complexas, que são chamados modelos High-Poly; e os modelos de malha simplificada, com baixa contagem de polígonos e que representam a geometria do objeto de forma mais básica e menos realista, conhecidos como modelos LowPoly. No entanto, o uso das tecnologias digitais na geração desses modelos permite fluxos de trabalho com etapas automatizadas, possibilitando a obtenção de resultados de modo mais rápido e preciso. Ainda assim, não se elimina a necessidade de análise e edição manual do modelo geométrico em alguma das etapas anteriormente apresentadas, uma vez que se busca a correta representação do objeto a ser digitalmente reconstruído.

A criação de ambientes virtuais interativos, seja dentro do contexto da gamificação e da produção de serious game, ou para aplicações mais simplificadas voltadas apenas para a visualização interativa, abrange processos complexos que envolvem diversas etapas de desenvolvimento e o domínio de diferentes softwares, métodos e técnicas em cada uma dessas etapas. Por conseguinte, novas ferramentas têm sido desenvolvidas, tanto para modelagem geométrica quanto para a criação de ambientes virtuais. Desse modo, ressalta-se a importância de se investigar novos métodos e tecnologias digitais, a partir de estudos e pesquisas no uso dos game engines para a visualização e difusão do patrimônio arquitetônico, visando o desenvolvimento de aplicações interativas.

Outra característica fundamental dos ambientes virtuais interativos é o seu funcionamento em tempo real, também chamado de tempo de reação do sistema ou latência, definido como “[...] o tempo entre a leitura dos dados de entrada e a respectiva renderização [...]” (TORI; HOUNSELL; KIRNER, 2018, p. 16). A interação no AVI 3D, desde uma simples movimentação para explorar o ambiente até ações mais complexas, precisam acontecer de forma imediata para proporcionar ao usuário a sensação de realidade e não causar desconforto. Nesse sentido, e considerando que as aplicações voltadas para o patrimônio devem ser de fácil difusão (baixos requisitos de processamento), os modelos geométricos a serem utilizados no ambiente virtual devem, por consequência, ter um tamanho de arquivo reduzido e uma quantidade otimizada de polígonos para que o processamento possa acontecer de forma rápida. Ou seja, é necessário o uso de modelos low-poly.

No contexto do patrimônio arquitetônico, a visualização do modelo geométrico deve ser a mais próxima do objeto real (ou seja, ter qualidade gráfica), representando os detalhes imprescindíveis para o seu reconhecimento. No entanto, conciliar a qualidade gráfica com um modelo low-poly requer o conhecimento de técnicas e softwares que possibilitem a geração de um modelo otimizado, sem resultar na perda de informações e detalhes relevantes, mantendo as características essenciais do modelo high-poly.

A seguir, são apresentados os estudos realizados envolvendo as técnicas de aquisição de dados geométricos e de texturas a partir da restituição fotogramétrica digital e diferentes processos de edição dos modelos, buscando o equilíbrio entre a qualidade gráfica e o número total de polígonos do modelo, bem como o tamanho final do arquivo.

O game engine Unreal Engine 4 (UE4) ${ }^{i i i}$, desenvolvido pela Epic Games, foi utilizado neste estudo por ser um software de uso gratuito ${ }^{\mathrm{iv}}$, consolidado no mercado, com possibilidade de programação a partir de uma linguagem visual de script chamada Blueprint, ter alta capacidade de processamento e por existirem plug-ins e templates específicos para a importação de modelos digitais arquitetônicos, compatíveis com os principais softwares de arquitetura, como Sketchup, Rhinoceros e Revit. 


\section{ESTUDO DE MODELOS GEOMÉTRICOS}

Este estudo apresenta a investigação de diferentes workflows e softwares para a modelagem geométrica de edificações históricas existentes, tendo como base o estudo iniciado em Linhares e Groetelaars (2019b), e partindo do processamento de 62 fotografias terrestres do objeto de estudo escolhido, no software Agisoft Photoscan (que trabalha com a técnica DSM), onde foram obtidos: um modelo de malha triangular irregular (Triangular Irregular Network - TIN) (Figuras 4a e 4b), uma malha TIN texturizada (Figura 4c) e uma ortofoto da fachada (Figura 4d). Inicialmente, foi selecionada uma edificação de geometria simplificada, focando na reconstrução de sua fachada principal, a fim de melhor compreender os processos a serem testados, o uso das ferramentas e os produtos que podem ser gerados.

Figura 4. Produtos obtidos no Agisoft Photoscan após o processamento das fotografias

Fonte: Elaboração das autoras.
Figura 5. Workflows definidos para o estudo da edição dos modelos geométricos

Fonte: Elaboração das autoras.
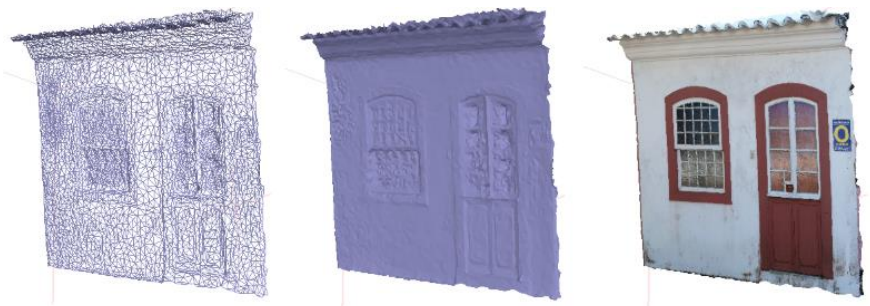

$$
\text { A) MALHA TIN }
$$
EM WIREFRAME
B) MALHA TIN EM COR SÓLIDA

\section{C) MALHA TIN} TEXTURIZADA

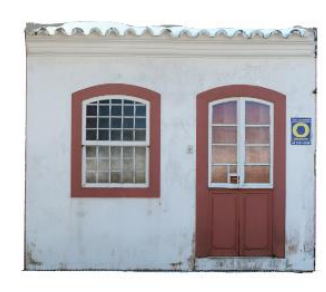

D) ORTOFOTO

O processamento das fotografias para a geração da malha TIN texturizada e da ortofoto (por DSM) foi descrito como workflow $1 \mathrm{e}$, partir desses resultados obtidos, foram definidos mais quatro workflows (Figura 5) com diferentes técnicas, que envolvem o pós-processamento desses produtos (malha TIN e ortofoto). Foram indicadas na figura, junto ao nome dos softwares utilizados, as etapas realizadas de forma automatizada com a letra (A), e de modo manual com a letra (M).

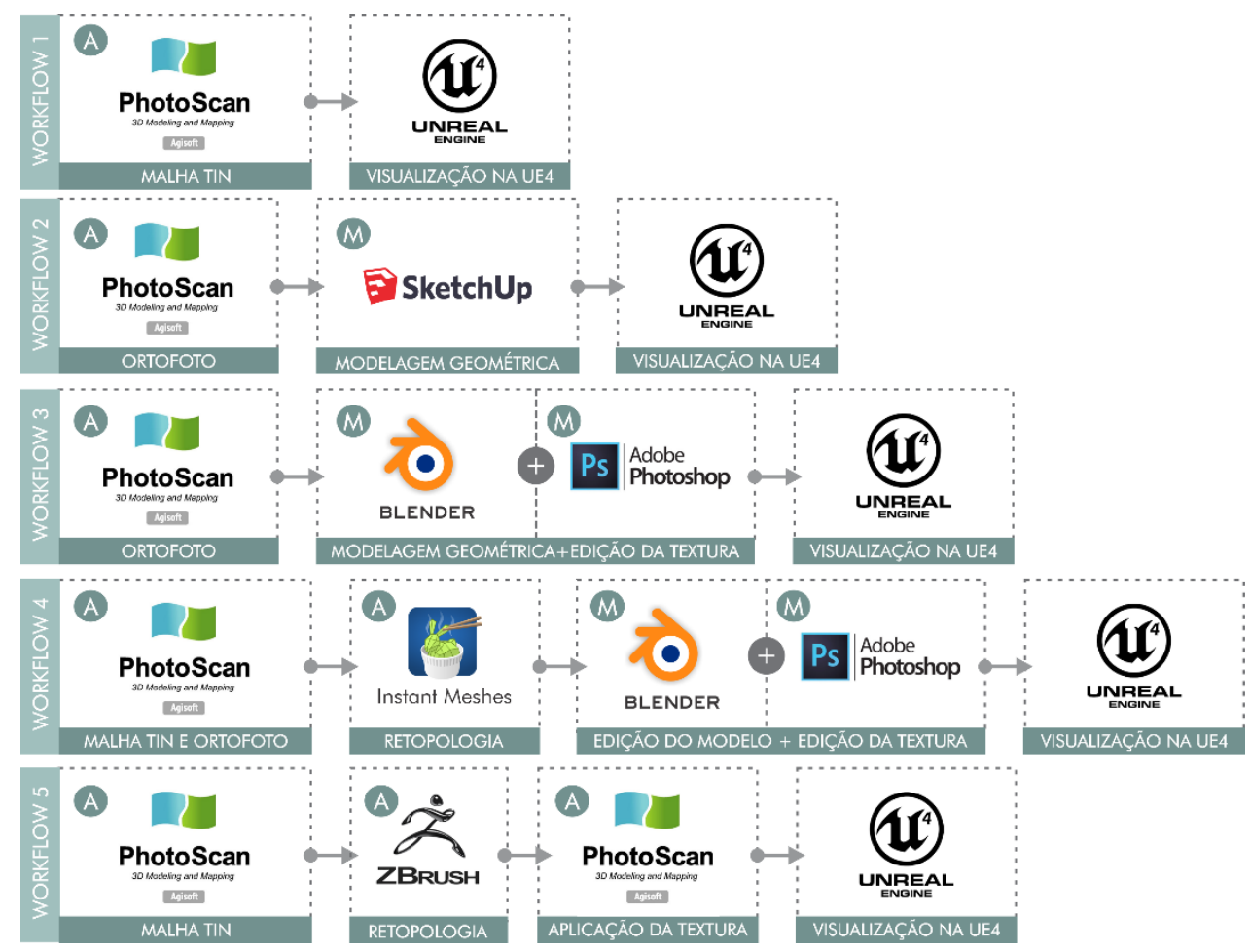


Após a produção e edição dos modelos geométricos nos cinco workflows, os mesmos foram inseridos na UE4 para analisar a qualidade gráfica final, considerando também: a quantidade total de polígonos do modelo, quando importado pela UE4 (que é diferente muitas vezes do arquivo original, uma vez que a UE4 realiza a triangulação de todas as faces do modelo geométrico); o tempo de processamentov, desde o produto inicial do workflow 1 até o modelo final; o tamanho final do arquivo nos formatos .FBX e .OBJ (Figura 6). Para uma melhor compreensão das geometrias geradas, os modelos também estão apresentados na visualização wireframe, a partir de imagens capturadas nos softwares onde os mesmos foram gerados, sendo possível identificar a composição da malha.
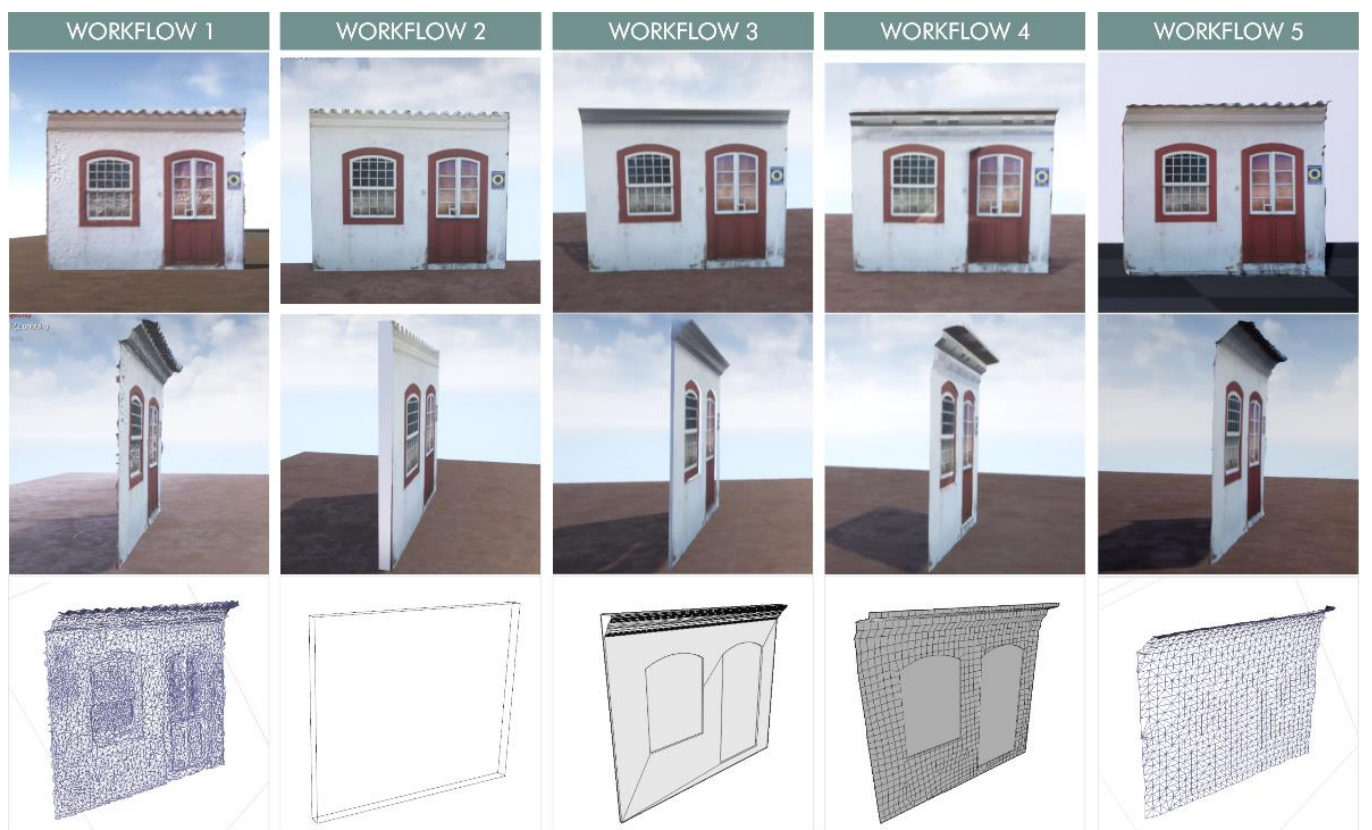

ORIGINAL | 7.684 POLIGONOS

UE4 | 7.684 POLIGINOS

TEMPO DE

PROCESSAMENTO

Malha TIN | $13 \min 15 \mathrm{~s}$

Textura | 4 min 36

Tempo total: $17 \mathrm{~min} 51 \mathrm{~s}$

ARQUIVO [.FBX]

COM TEXTURA: $228 \mathrm{~KB}$

SEM TEXTURA: 156 KB

ARQUIVO [.OBJ]:

COM TEXTURA: $692 \mathrm{~KB}$

SEM TEXTURA: 513 KB

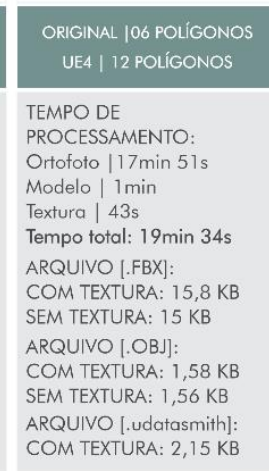

ORIGINAL | 55 POLIGONOS
UE4 | 242 POLIGONOS

TEMPO DE

$17 \mathrm{~min} 51 \mathrm{~s}$

Modelo | 1h $10 \mathrm{~min}$

Textura | $23 \mathrm{~min}$

Tempo total: $1 \mathrm{~h} 50 \mathrm{~min} 51 \mathrm{~s}$

ARQUIVO [.FBX]:

COM TEXTURA: $37,4 \mathrm{~KB}$

SEM TEXTURA: $31,8 \mathrm{~KB}$

ARQUIVO [.OBJ]:

COM TEXTURA: $21,0 \mathrm{~KB}$

SEM TEXTURA: 8,54 KB
PROCESSAMENTO

Nuvem de pontos + Ortofoto

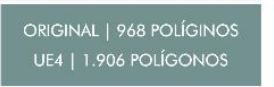

TEMPO DE

PROCESSAMENTO:

Malha TIN | $13 \mathrm{~min} 15 \mathrm{~s}$

Retopol. Autom. | $1 \mathrm{~min}$

Retopol. Manual | $32 \mathrm{~min}$

Textura | $25 \mathrm{~min}$

Tempo total: $1 \mathrm{~h} 12 \mathrm{~min} 15 \mathrm{~s}$

ARQUIVO [.FBX]:

COM TEXTURA: $85,3 \mathrm{~KB}$

SEM TEXTURA: $81,9 \mathrm{~KB}$

ARQUIVO [.OBJ];

COM TEXTURA: $138 \mathrm{~KB}$

SEM TEXTURA: $93 \mathrm{~KB}$

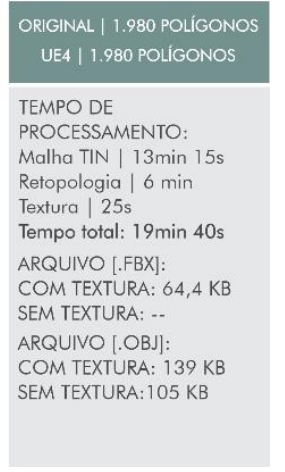

No workflow 1, o modelo high-poly de malha TIN gerado inicialmente no Agisoft Photoscan foi importado diretamente na UE4. Apesar de ser um processo rápido e com pouco ou nenhum trabalho manual, o modelo obtido apresenta uma malha TIN densa e com muitas irregularidades visíveis (em trechos planos da parede), o que torna inadequada a sua utilização direta no game engine. 0 tamanho final do arquivo, com ou sem a textura aplicada, demonstrou ser o mais alto entre os workflows estudados.

No workflow 2 foi realizada uma modelagem geométrica simplificada no software Sketchup, tendo como base a ortofoto da fachada gerada no workflow 1 . A mesma imagem foi aplicada no plano principal do modelo, como textura. Para possibilitar a correta importação do modelo na UE4, uma vez que o Sketchup não exporta o mapeamento da textura necessário, foi utilizado o plug-in Datasmith (fornecido gratuitamente pela Epic Games vi ). 0 plug-in permite a

Figura 6. Visualização dos modelos geométricos texturizados na Unreal Engine 4, representação em wireframe e dados sobre os modelos gerados em cada workflow

Fonte: Elaboração das autoras. 
exportação completa do modelo do Sketchup com a textura (formato .udatasmith) e reduziu o tamanho do arquivo para $4 \mathrm{~KB}$, sem a geração de arquivos externos adicionais. Para a contagem total do tempo de geração do modelo, considerou-se também o tempo de geração da ortofoto no workflow 1. 0 modelo low-poly gerado é o mais simplificado de todos os workflows apresentados e o mais limitado, uma vez considera a fachada completamente plana, desconsiderando detalhes como a cimalha e o beiral.

No workflow 3 foi gerado um modelo low-poly no software Blender, a partir da ortofoto e da nuvem de pontos, ambas geradas no workflow 1 . Por não ser um software de domínio das autoras, e por ter sido realizada uma modelagem mais detalhada em relação ao workflow 2, o processo foi mais demorado. Para a etapa de texturização, foi necessário realizar um mapeamento de textura no próprio Blender, em paralelo com o Adobe Photoshop. 0 modelo geométrico teve suas superfícies separadas em grupos para depois ter a sua geometria planificada, gerando um mapa de texturas UV (2D). Cada textura referente a uma superfície da edificação, conforme a planificação realizada, foi recortada da ortofoto e aplicada ao modelo (Figura 7).

Figura 7. Processo de mapeamento de textura do workflow 3 (no Blender)

Fonte: Elaboração das autoras.

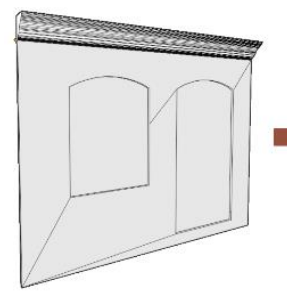

MODELO GEOMÉTRICO

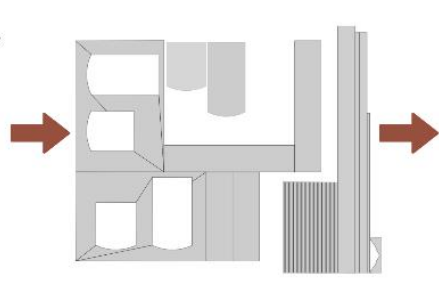

MAPA DE TEXTURAS UV

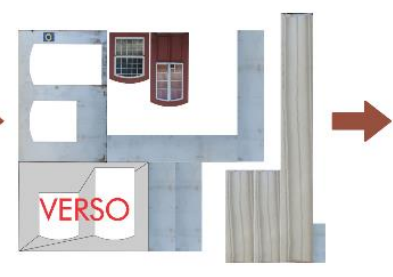

MAPEAMENTO UV DAS TEXTURAS

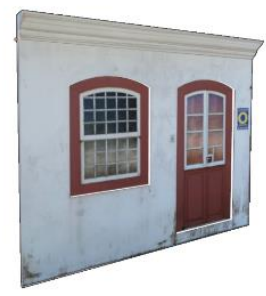

MODELO GEOMÉTRICO COM TEXTURA APLICADA

Tanto o processo de modelagem quanto o de mapeamento de textura demandaram um tempo de trabalho manual considerável que, embora possa ser reduzido com a prática em utilizar as ferramentas do programa, ainda demonstra ser um workflow demorado. 0 software Blender exporta o mapeamento de textura junto do modelo geométrico, nos formatos .FBX e .OBJ, não sendo necessário o uso de plug-in. Por fim, para a contagem total do tempo de processamento do modelo, também considerou-se o tempo de geração da ortofoto e da nuvem de pontos do workflow 1.

No workflow 4 optou-se por trabalhar com a malha TIN gerada inicialmente no workflow 1 (modelo high-poly), uma vez que a mesma já possuía a geometria da edificação, evitando o processo inicial de modelagem. Para tentar corrigir os problemas de irregularidade da malha, e de sua alta densidade de representação, realizou-se a retopologia do modelo, ou seja, uma reestruturação da malha com o objetivo de simplificá-la. 0 modelo high-poly foi então importado no programa Instant Meshes, que realizou a retopologia de forma automática, resultando em um modelo low-poly de malha quadrangular, ou malha quad, com menor densidade. Para deixar o modelo mais próximo à edificação original, e para o mapeamento de textura, a nova malha foi importada no Blender, onde a retopologia foi continuada manualmente, ajustando detalhes como o contorno da fachada, a cimalha e as esquadrias. A textura foi mapeada da mesma forma descrita no workflow 3 e como resultado obteve-se um modelo low-poly texturizado (Figura 8). 


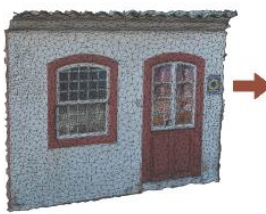

MALHA TIN ORIGINAL COM TEXTURA

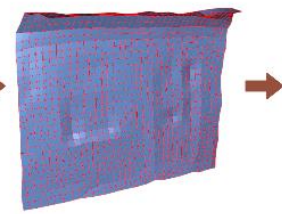

MALHA QUAD SEM TEXTURA [RETOPOLOGIA AUTOMÁTICA]

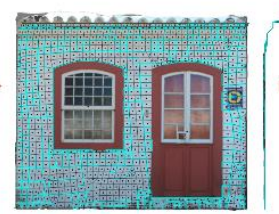

MALHA QUAD + ORTOFOTO [RETOPOLOGIA MANUAL]

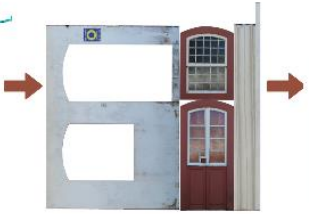

MAPA DE TEXTURA UV

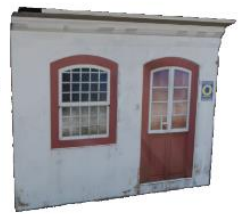

MODELO GEOMÉTRICO FINAL COM TEXTURA APLICADA

No entanto, devido a algumas irregularidades que permaneceram na malha, pequenas deformações são perceptíveis no modelo final. Um processo de retopologia manual mais minucioso poderia corrigir as irregularidades, porém aumentaria consideravelmente o tempo de geração do modelo. Este workflow não apresentou vantagem em comparação ao workflow 3 , uma vez que o tempo de geração do modelo foi próximo e a contagem de polígonos, bem como o tamanho dos arquivos, maior. Por se tratar de uma geometria simples, o processo de modelagem manual permite a geração mais controlada de um modelo low-poly.

No workflow 5, o modelo high-poly de malha TIN gerado no workflow 1 foi importado no software Zbrush para o processo de retopologia automática. Esse software permite um maior controle na etapa automatizada por meio da escolha de parâmetros que irão determinar as modificações da malha. Neste processo, é possível realizar a retopologia automática sem deformações consideráveis na geometria, possibilitando a transformação da malha triangular em uma malha quad, além de reduzir sua densidade, sem prejudicar a forma do objeto. Quanto maior a simplificação da malha, mais deformações irão acontecer, sendo portanto necessário encontrar um equilíbrio entre a contagem total de polígonos e a representação adequada da geometria, coerente com as formas reais do objeto e com as aplicações do modelo.

Com o processo de retopologia automática, um novo modelo low-poly é obtido e importado novamente no Agisoft Photoscan, no mesmo arquivo do modelo high-poly original. 0 primeiro modelo (arquivo original high-poly) é então substituído pelo novo modelo (low-poly) e a textura é novamente processada para a aplicação no novo modelo. Nesse processo de texturização, utiliza-se o mapeamento de texturas já salvo do modelo original, desse modo, as características do modelo high-poly são visualmente aplicadas no modelo low-poly. Como resultado, tem-se um novo modelo com malha reduzida e com tamanho de arquivo menor, porém com a riqueza de detalhes visualmente bem próxima do modelo em malha densa (Figura 9).

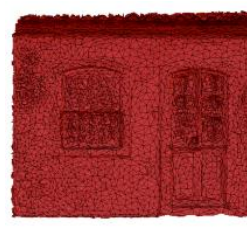

MODELO GEOMÉTRICO HIGH-POLY [MALHA TIN]

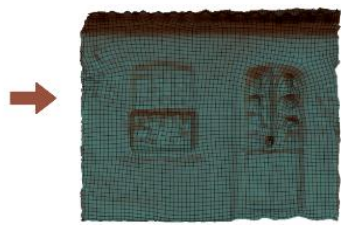

PROCESSO DE RETOPOLOGIA AUTOMÁTICA [MALHA QUAD]

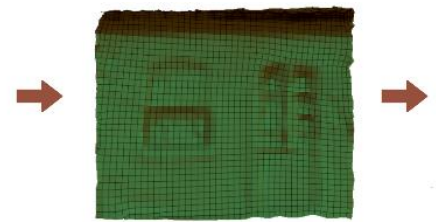

MODELO GEOMÉTRICO LOW-POLY [MALHA QUAD]

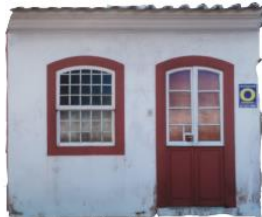

MODELO LOW-POLY COM TEXTURA [MALHA QUAD]

0 processo de retopologia automática do workflow 5 também corrige algumas das irregularidades de superfícies planas do modelo, o que torna sua visualização no game engine mais adequada. Maiores correções também podem ser feitas através de retopologia manual no próprio software Zbrush, ou em outros softwares de modelagem geométrica. Para o estudo mais completo do workflow 5, diferentes níveis de retopologia foram realizadas no Zbrush, iniciando com a malha original de 7.684 polígonos e reduzindo gradualmente até uma malha de 214 polígonos, gerando quatro modelos de malha com diferentes quantidades de polígonos. Os modelos foram inseridos e texturizados no Agisoft Photoscan e o resultado final comparado, de forma a identificar, para este modelo, qual a redução máxima permitida sem deformar a geometria do objeto (Figura 10). 
Figura 10.

Comparação visual

dos modelos gerados

no processo de

retopologia

automática no

software Zbrush (B a

E), a partir do modelo

original $(A)$

Fonte: Elaboração das autoras.

Figura 11. Resultado do processamento do workflow 1 com uma edificação de geometria mais complexa

Fonte: Elaboração das autoras.
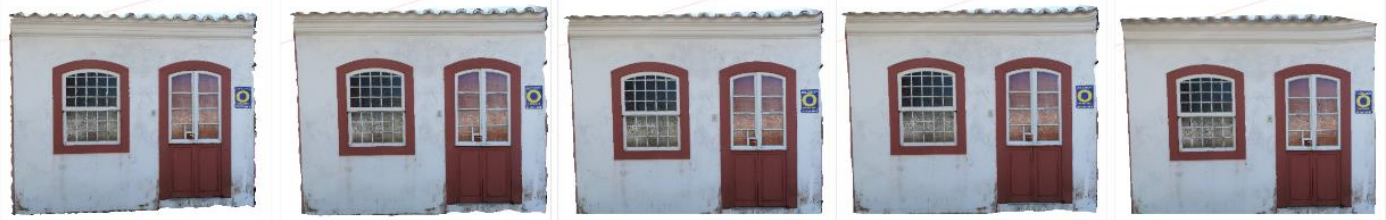

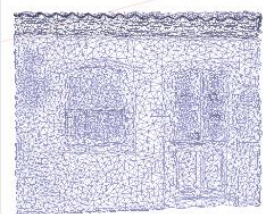

A) 7,684 POLIGONOS

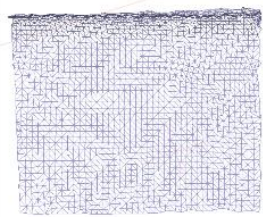

B) 3,837 POLÍGONOS

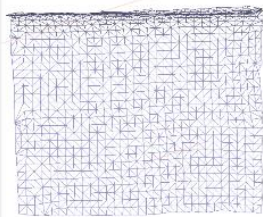

C) 1,980 POLÍGONOS

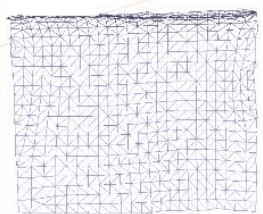

D) 1,162 POLIGONOS

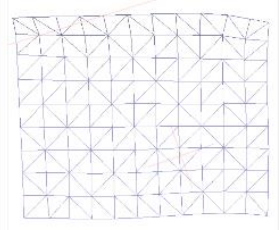

E) 214 POLIGONOS

Os resultados $\mathrm{B}$ e $\mathrm{C}$ apresentaram malhas mais adequadas, sem deformar a geometria, tendo como referência a malha original A. Já os modelos D e E apresentaram deformações consideráveis, no contorno e nas dimensões da edificação, assim como nas aberturas, e não são adequados para a utilização no game engine. 0 resultado final $\mathrm{C}$ foi o escolhido para a inserção na UE4, uma vez que apresentou a menor contagem de polígonos sem deformações significativas na forma do objeto. 0 tempo de processamento deste workflow é baixo e o mesmo é realizado de forma automática, sendo necessário trabalho manual apenas para a correção de deformações específicas da malha, quando conveniente. Devido à impossibilidade de exportar o modelo no formato .FBX no software Zbrush (modelo final sem textura), foi considerado para a análise, o modelo final texturizado que apresentou tamanho significativo, embora menor em comparação com o arquivo do modelo original.

Para o aprofundamento do estudo apresentado, optou-se por testar os workflows descritos em um objeto de geometria mais complexa. Foi escolhida uma edificação isolada para o processamento através do workflow 1, desta vez a partir de 116 fotografias aéreas para capturar toda a geometria da mesma. 0 modelo high-poly obtido no processamento apresentou qualidade final média, uma vez que não haviam fotos suficientes para gerar um modelo de alta qualidade, mas a geometria e texturização foram consideradas satisfatórias para este estudo (Figura 11). Não foram geradas ortofotos para este modelo, uma vez que as mesmas apresentariam grandes irregularidades devido à má formação do modelo em algumas partes, e por conseguinte não seriam adequadas para a utilização nos outros workflows.

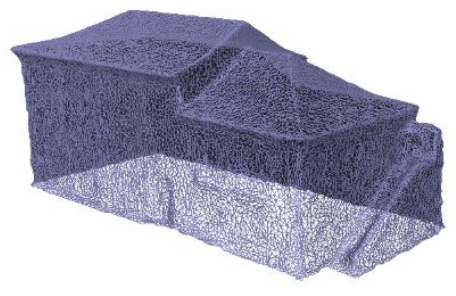

MALHA TIM EM WIREFRAME

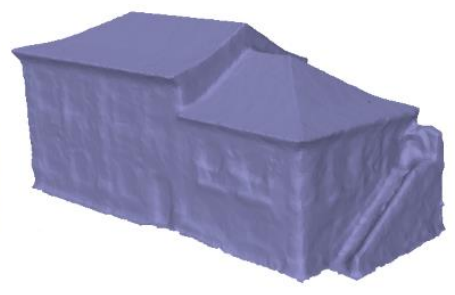

MALHA TIN EM COR SÓLIDA

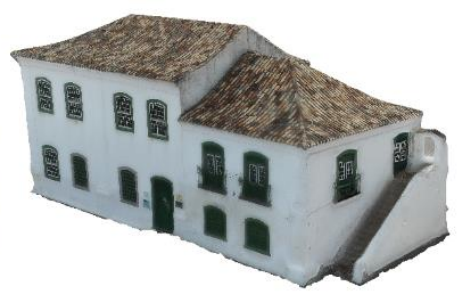

MALHA TIN TEXTURIZADA

Devido à impossibilidade de geração de ortofotos precisas e adequadas, necessárias para o processamento de modelos realistas nos workflows 2 e 3, optou-se por testar apenas adaptações dos workflows 4 e 5 (que usam retopologia automática) no novo modelo. Ressaltase que o workflow 3 poderia ser realizado utilizando apenas a nuvem de pontos, mas o mapeamento de texturas com as ortofotos levariam, neste caso (devido às deformações das ortofotos), a uma texturização imprecisa. Logo, para este tipo de edificação, os workflows que trabalham diretamente com a malha obtida, tornam-se mais adequados. 
Para este estudo, portanto, optou-se por testar os métodos de retopologia automática dos workflows 4 e 5 (Instante Meshes e Zbrush), seguidos do processo de texturização do workflow 5 (Agisoft Photoscan), uma vez que esses métodos de processamento mostraram-se rápidos, automatizados e com bom resultado quanto à qualidade gráfica final. Os três modelos foram colocados na UE4 e comparados quanto à qualidade da visualização, contagem de polígonos, tempo de processamento e tamanho final dos arquivos (Figura 12).
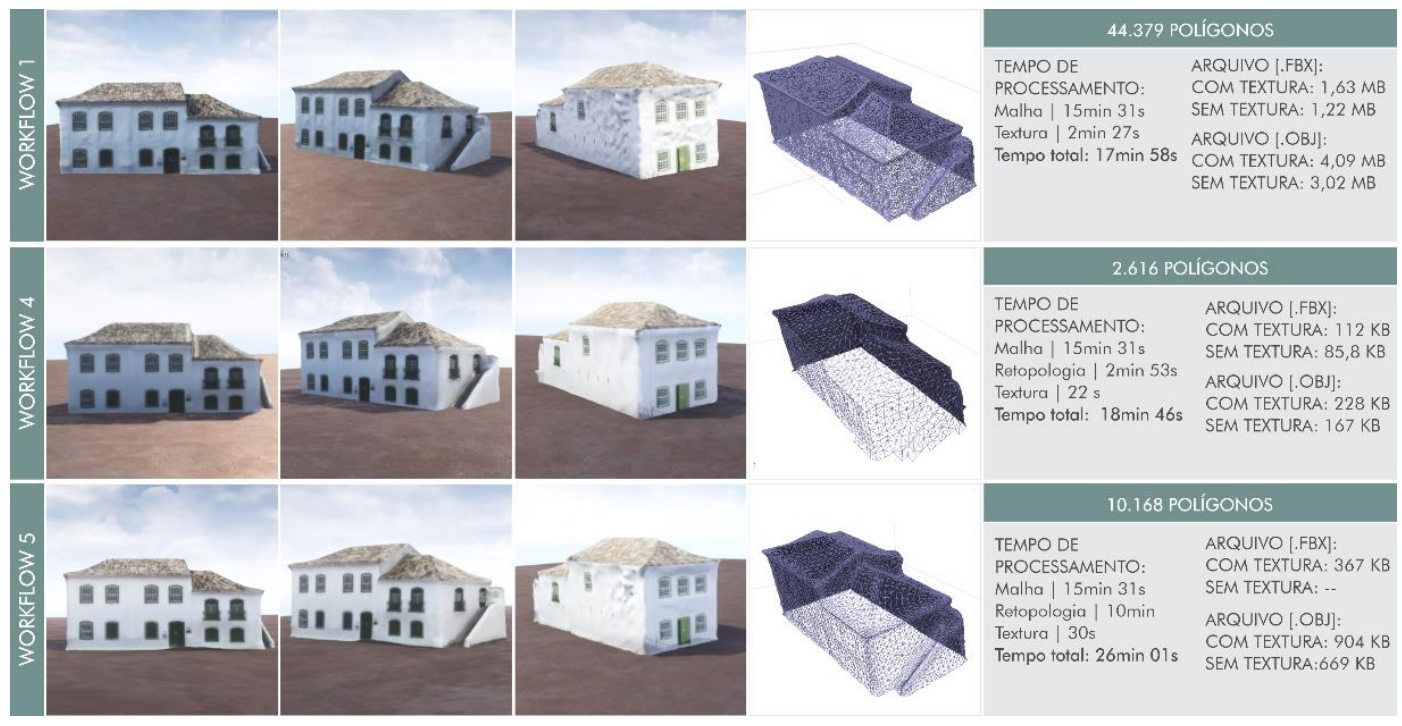

No workflow 1, os modelos dessa nova edificação, assim da fachada apresentada anteriormente, apresentaram alta contagem de polígonos e inúmeras deformações na malha, que são visíveis na UE4, comprovando a necessidade de retopologia do modelo. Ressalta-se que a maior diferença entre os softwares de retopologia automática utilizados nos workflows 4 e 5 refere-se ao tipo de controle das transformações a serem aplicadas no modelo. Enquanto o Instant Meshes (workflow 4) simplifica de forma relevante a malha e a geometria, o Zbrush (workflow 5) permite um maior controle nos parâmetros de decimação da malha.

No modelo da edificação completa, a retopologia do workflow 4 simplificou os planos das fachadas, fazendo com que algumas deformações fossem atenuadas. No entanto, algumas alterações quanto às dimensões e detalhes do modelo original também foram modificadas, fazendo com que o novo modelo low-poly não fosse tão preciso, embora visivelmente essas mudanças não sejam muito perceptíveis. Já no workflow 5 , algumas das deformações geradas foram mantidas, uma vez que o processo de retopologia automática respeita a geometria do high-poly. Porém, as dimensões do modelo original não sofreram alterações relevantes (Figura 13).
Figura 12. Visualização do modelo de geometria mais complexa no Unreal Engine 4 e no Photoscan (em wireframe)

Fonte: Elaboração das autoras. 
Figura 13. Visualização de uma parte dos modelos gerados

Fonte: Elaboração das autoras.
Reconstrução digital do patrimônio arquitetônico para ambientes virtuais interativos 3D: estudo de métodos para modelagem geométrica de edificações existentes

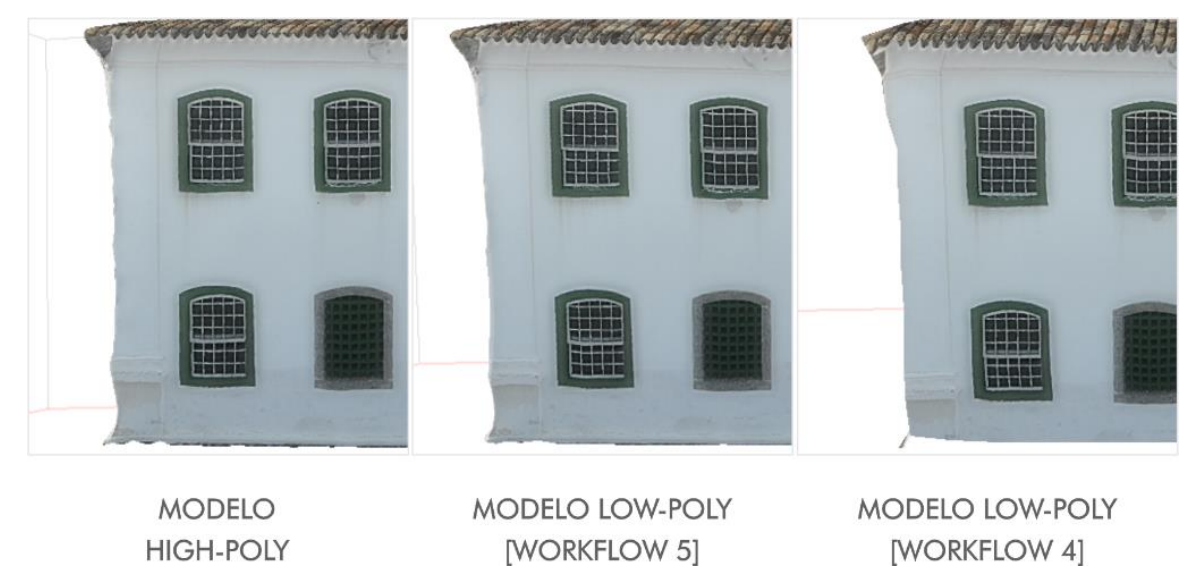

Por fim, observa-se que para o processamento de um modelo geométrico realista, preciso, com boa qualidade gráfica e otimizado, são necessários: (1) um cuidadoso processo de restituição fotogramétrica digital, incluindo uma tomada fotográfica adequada, registrando a edificação em diversos ângulos e em diferentes alturas, para que se possa gerar um modelo high-poly preciso e com texturas de elevada qualidade; (2) processos de retopologia automática, para a simplificação da malha, e (3) processos de retopologia manual, para corrigir eventuais deformações. Os processos de modelagem manual também podem ser utilizados para gerar modelos geométricos de edificações existentes, porém demandam mais tempo e podem, muitas vezes, levar a maiores imprecisões no resultado final, uma vez que dependem da interpretação de imagens (2D) para a geração do modelo (3D).

\section{CONSIDERAÇÕES FINAIS}

A modelagem geométrica de edificações históricas existentes, tendo em vista seu uso para a criação de ambientes virtuais interativos (AVI), é um processo complexo que envolve diversas etapas e softwares. A inserção de modelos geométricos em um game engine para a criação de AVI 3D voltados ao patrimônio, seja com o objetivo de criar aplicações de realidade virtual não imersiva, um simples tour virtual, até aplicações de realidade virtual imersiva e serious game, dependem fundamentalmente de modelos geométricos que apresentem: boa qualidade gráfica, de forma a representar todas as características imprescindíveis para o reconhecimento do objeto histórico; geometria otimizada, para que não prejudiquem o processamento da aplicação em tempo real; e boa precisão na representação dos objetos reais. Essas características são importantes para que o AVI possa atingir o seu objetivo de fazer com que o usuário se sinta presente no ambiente virtual, ao mesmo tempo em que pode visualizar e interagir com o patrimônio edificado, representado de forma fidedigna.

Este estudo apresentou algumas possibilidades de produção de modelos geométricos de edificações existentes, partindo de produtos obtidos através de técnicas fotogramétricas. 0 processamento de fotografias, seja para a geração de modelos de malha triangular irregular, ou para a produção de ortofotos, é uma técnica automatizada que permite a rápida obtenção da geometria da edificação, bem como de mapas de textura realistas. Apesar das potencialidades desses modelos, quando se trata de AVI, recomenda-se sua manipulação ou edição para gerar versões otimizadas dos modelos geométricos. Dentre os métodos de edição, destacam-se os processos de retopologia manual e automática, que possibilitam a obtenção de modelos realistas de modo mais ágil e preciso.

Os workflows apresentados expõem apenas alguns métodos e ferramentas para a geração de modelos low-poly através de processos de retopologia e modelagem geométrica manual, não existindo uma única forma correta de processamento de edificações históricas existentes. 0 
workflow mais adequado dependerá de uma série de fatores, dentre os quais destacam-se: características do objeto a ser virtualmente reconstruído, seu entorno e condicionantes; recursos e equipamentos disponíveis; grau de conhecimento de técnicas de processamento dos modelos e de softwares; nível de detalhe e fidelidade pretendido, em função dos objetivos da aplicação e da forma de difusão do AVI, dentre outros.

Portanto, ressalta-se a importância de se investigar métodos, técnicas e ferramentas para o processamento de modelos geométricos de edificações existentes em low-poly, em diferentes escalas e graus de complexidade, de forma a identificar novos fluxos de trabalho que possam ser mais adequados às necessidades específicas de cada objeto.

0 método manual de mapeamento de textura realizado nos workflows 3 e 4 demandou maior tempo e trabalho do que nos outros métodos, uma vez que necessita o recorte manual de cada face da ortofoto para ser aplicada no modelo. Esse método é também sensível à habilidade e cuidado do operador, podendo resultar em modelos imprecisos se não for feito de forma correta. Por outro lado, imagens genéricas podem ser utilizadas para a texturização do modelo, a depender do nível de realismo pretendido, tornando o processo de mapeamento mais rápido. Por fim, para ambos os casos, técnicas de renderização, como uso de mapas espaciaisvii para a geração de relevos, podem ser aplicadas para obter um modelo mais realista.

0 método utilizado no workflow 5 mostrou ser o mais interessante, uma vez que todo o seu processo é realizado de forma automatizada e o resultado final apresentou-se adequado. 0 mapa de textura gerado no modelo high-poly, quando aplicado no modelo low-poly, permite a representação visual dos detalhes da geometria complexa na malha simplificada. No entanto, ressalta-se que para obter um bom resultado neste workflow, é necessário que o modelo highpoly apresente boa qualidade (geometria e textura), o que necessita de um processo de restituição fotogramétrica adequado, incluindo a elevada qualidade da tomada fotográfica do objeto de interesse. Quanto menos deformações foram geradas no modelo high-poly, maior será a qualidade do modelo final e menor será o trabalho de retopologia manual para corrigir possíveis problemas na malha.

Quanto à contagem final de polígonos do modelo e o tamanho do arquivo, os mesmos também irão depender de cada situação específica. Em aplicações mais simples, com o uso de poucos modelos geométricos, é possível trabalhar com arquivos maiores e com malhas mais densas, enquanto em aplicações com maiores níveis de interatividade e grande quantidade de modelos geométricos, faz-se necessário buscar modelos mais simplificados. 0 equilíbrio entre qualidade visual (relacionada à forma geométrica e texturização) e capacidade de processamento mostrase fundamental em qualquer aspecto do uso de modelos geométricos em ambientes virtuais interativos 3D. Ressalta-se também que a capacidade de processamento do computador utilizado, o conhecimento específico em métodos de modelagem geométrica, bem como as habilidades do operador nas ferramentas apresentadas, influenciam diretamente nos resultados.

Outro ponto a ser explorado são os recursos oferecidos pelos game engines para otimizar o processamento de modelos geométricos em aplicações interativas. Alguns motores de jogos, como a UE4, permitem a vinculação de modelos geométricos com diferentes níveis de detalhe, que vão sendo processados e substituídos à medida em que o usuário se aproxima do objeto. Dessa forma, é possível utilizar tanto modelos high-poly quanto modelos low-poly na aplicação.

Por fim, ressalta-se que com a demanda crescente de soluções eficientes e eficazes para a preservação e difusão patrimônio arquitetônico e de sítios históricos, com os constantes avanços tecnológicos e o surgimento de novas ferramentas, torna-se imprescindível a realização de estudos visando otimizar e aprimorar o processamento dos modelos geométricos utilizados em Ambientes Virtuais Interativos. 


\section{Agradecimentos}

As autoras registram seus agradecimentos ao Conselho Nacional de Desenvolvimento Científico e Tecnológico - CNPq pelo apoio à pesquisa de mestrado em curso.

\section{Referências Bibliográficas}

ANDERSON, E. F. et al. Serious game in cultural heritage. In: INTERNATIONAL SYMPOSIUM ON VIRTUAL REALITY, ARCHAEOLOGY AND CULTURAL HERITAGE, 10., 2009, St. Julians. Proceedings [...]. St. Julians: Eurographics Association, 2009 p. 29-48. ISBN 9783905674187.

AMORIM, A. L. Methodological aspects of architectural documentation. Geoinformatics FCE CTU, v.6, p. 34-39, 2011. DOI 10.14311/gi.6.5.

CAMARA, J. Jogos sérios e mediação patrimonial: estratégias de identificação, valorização e transmissão do património cultural imaterial. Memoriamedia, v. 3, n. 4, 2018. ISSN 21833753.

CHAMPION, E. Entertaining the similarities and distinctions between serious games and virtual heritage projects. Entertaining Computing, 2015. E-book. DOI 10.1016/j.entcom.2015.11.003.

DENARD, H. (ed.). For the computer-based visualisation of cultural heritage. 2009. Disponível em: http://www.londoncharter.org/. Acesso em: 18 abr. 2019.

GROETELAARS, N. J. Criação de Modelos BIM a partir de "nuvem de pontos": estudo de métodos e técnicas para documentação arquitetônica. 2015. Tese (Doutorado em Arquitetura e Urbanismo) - Faculdade de Arquitetura, Universidade Federal da Bahia, Salvador, 2015.

IOANNIDES, M., MAGNENAT-THALMANN, N., PAPAGIANNAKIS, G. (ed.). Mixed reality and gamification for cultural heritage. Springer International Publishing, 2017. E-book. DOI 10.1007/978-3-319-49607-8.

JERALD, J. The VR book: human-centered for virtual reality. 1 ed. ACM Books, 2016. E-book. DOI $10.1145 / 2792790$.

LINHARES, G.; GROETELAARS, N. J. Realidade virtual para a visualização e difusão do patrimônio arquitetônico: conceitos e aplicações. In: ENCONTRO BRASILEIRO DE MODELAGEM DA INFORMAÇÃO DA CONSTRUÇÃO E PATRIMÔNIO CULTURAL, 1., 2019, São Carlos, SP. Anais [...]. São Carlos: IAU-USP, 2019a.

LINHARES, G.; GROETELAARS, N. J. Tecnologias digitais para a representação do patrimônio arquitetônico: estudo de métodos para modelagem geométrica. In: ENCONTRO BRASILEIRO DE MODELAGEM DA INFORMAÇÃO DA CONSTRUÇÃO E PATRIMÔNIO CULTURAL, 1., 2019, São Carlos, SP. Anais [...]. São Carlos: IAU-USP, 2019b.

LIAROKAPIS, F. et al. Multimodal serious game technologies for cultural heritage. In: IOANNIDES, M.; MAGNENAT-THALMANN, N.; PAPAGIANNAKIS, G. (ed.). Mixed reality and gamification for cultural heritage. Springer International Publishing, 2017. E-book.

MARCHI, P.; HASHIMOTO, M. Arquitetura e Design. In: TORI, R.; HOUNSELL, M. S. (org.). Introdução a realidade virtual e aumentada. Porto Alegre: SBC, 2018. E-book. ISBN 978-857669-446-5.

MCGONIGAL, J. Gaming can make a better world. In: TED: Ideas worth spreading. 2010. Disponível em: https://www.ted.com/talks/jane_mcgonigalgaming_can_make_a_better_world?utm_source=f 
acebook.com\&utm_medium=social\&utm_campaign=tedspread\&fbclid=IwAR2Gfp0cc4KCgDQ uScpA4AoAZ3T2HZ1M2fDEkEKxWUVMuQnjJmVoh2b4k\#t-867. Acesso em: 16 de jun. 2019.

MORTARA, M. et al. Learning cultural heritage by serious game. Journal of Cultural Heritage, Elsevier, v. 15, n. 3, p. 318-325, 2014. DOI 10.1016/j.culher.2013.04.004.

NOGUEIRA, F. M. S. A representação de sítios históricos: documentação arquitetônica digital. 2010. Dissertação (Mestrado em Arquitetura e Urbanismo) - Faculdade de Arquitetura, Universidade Federal da Bahia, Salvador, 2010.

ROSA JUNIOR, O. LRVCHAT3D, desenvolvimento de um ambiente virtual tridimensional multiusuário para internet. Dissertação (Mestrado em Engenharia de Produção) Universidade Federal de Santa Catarina, 2003.

STATHAM, N. Scientific rigour of online plataforms for 3D visualisation of heritage. Virtual Archaeology Review, v. 10, n. 21, p.1-16, 2019. DOI 10.4995/var.2019.9715.

TORI, R.; HOUNSELL, M. S.; KIRNER, C. Realidade Virtual. In: TORI, R.; HOUNSELL, M. S. (org.). Introdução a realidade virtual e aumentada. Porto Alegre: SBC, 2018. E-book. ISBN 978-857669-446-5.

\section{Notas}

\footnotetext{
' Motor gráfico desenvolvido para a produção de jogos digitais, popularmente utilizado para o desenvolvimento de diferentes tipos de ambientes virtuais interativos.

ii Do inglês gamification - aplicação de mecânicas, dinâmicas e estratégias de jogos em contexto de não-jogo, buscando envolver e sustentar a participação do usuário (LIAROKAPIS et al., 2017).

iii Disponível em https://www.unrealengine.com/en-US/.

iv A desenvolvedora Epic Games disponibiliza o software gratuitamente, sendo necessário pagamento apenas se a aplicação produzida obtiver lucro acima de uma quantia de dólares definida.

${ }^{\vee}$ Ressalta-se que o tempo de processamento foi computado para fins comparativos deste estudo, podendo o mesmo variar em função: da capacidade de processamento do computador utilizado, do conhecimento técnico, bem como das habilidades do operador no uso das ferramentas. vi Disponível em https://www.unrealengine.com/en-US/datasmith?sessionInvalidated=true.

vii O uso de mapas especiais como Normal Map, Bump Map e Displacement Map é uma técnica de renderização de modelos geométricos utilizada para dar a sensação visual da existência de relevo em uma malha simplificada, sem a necessidade de uso de modelos muito detalhados.
}

Gabriela Linhares da Silva gabils.ara93@gmail.com

Natalie Johanna Groetelaars natgroet@ufba.br 